\title{
RENDIMENTO TÉRMICO E EMISSÕES DE CONTAMINANTES ATMOSFÉRICOS DE GASOLINAS FORMULADAS COM ETANOL, MTBE E TAEE
}

\author{
Rosângela da Silva, Eliana Weber de Menezes e Renato Cataluña* \\ Departamento de Físico-Química, Instituto de Química, Universidade Federal do Rio Grande do Sul, Av. Bento Gonçalves, \\ 9500, 91501-970 Porto Alegre - RS, Brasil
}

Recebido em 3/1/07; aceito em 14/10/07; publicado na web em 24/7/08

\begin{abstract}
THERMAL YIELD AND EMISSION OF ATMOSPHERIC CONTAMINANTS FROM GASOLINES FORMULATED WITH ETHANOL, MTBE AND TAEE. The specific consumption and carbon monoxide (CO) and nitrogen oxide (NO) emissions from gasolines formulated with ethanol, methyl tert-butyl ether (MTBE) and tert-amyl ethyl ether (TAEE) were evaluated in the rich, stoichiometric and lean-burn regions during the operation of an Otto-cycle engine. The use of ethanol as an additive presented high specific consumption, while gasoline formulated with TAEE showed low specific consumption with the engine operating under lean-burn conditions. The ethers evaluated here presented a low percentage of $\mathrm{CO}$ in the rich-burn region when compared with ethanol.
\end{abstract}

Keywords: fuels; oxygenated additive; Otto-cycle engine.

\section{INTRODUÇÃO}

Atualmente, há um grande interesse mundial em reduzir as emissões de contaminantes atmosféricos e em aumentar a eficiência dos motores de combustão interna. ${ }^{1-4} \mathrm{~A}$ formulação de gasolina utilizando álcoois e éteres é uma prática freqüente para melhorar a qualidade dos combustíveis..$^{5-9}$ Muitos trabalhos demonstram a redução nos níveis de emissões de contaminantes com a utilização de gasolinas formuladas com etanol. ${ }^{10,11}$ Entretanto, devido à baixa entalpia de combustão do etanol, ocorre um aumento no consumo proporcional a essa diferença. Os compostos oxigenados possuem elevado número de octano, fato que favorece a qualidade da combustão $0^{9,12,13} \mathrm{em}$ virtude da presença do átomo de oxigênio. Isso contribui para a diminuição das emissões de monóxido de carbono e hidrocarbonetos não queimados. Gasolinas formuladas com etanol apresentam elevada pressão de vapor. ${ }^{14}$ No caso da presença de água, ocorrerá separação entre fases, separando o álcool na fase aquosa. ${ }^{15}$ Já no caso dos éteres, como estes têm maior similaridade com hidrocarbonetos que com água, isso não ocorre. Os éteres têm ainda a seu favor uma baixa volatilidade, o que ocasiona reflexo na diminuição da pressão de vapor da gasolina formulada.

A entalpia de combustão é um parâmetro importante na análise do combustível, influenciando diretamente na magnitude da produção de trabalho. A volatilidade também influencia no desempenho do motor. Combustíveis com baixa volatilidade e altas densidades resultam em maior trabalho realizado por volume de combustível. Combustíveis com baixa pressão de vapor aumentam a eficiência volumétrica de um motor devido à redução da temperatura da massa de gases de admissão, aumentando a densidade da mistura ar/combustível. Frações com elevado peso molecular apresentam maior entalpia de vaporização. Os valores de entalpia de combustão são em torno de $43 \mathrm{~kJ} \mathrm{~kg}^{-1}$ para gasolinas que não contêm compostos oxigenados. ${ }^{8,16}$ Outro parâmetro importante é a velocidade de queima do combustível. Em motores bem projetados, a turbulência dentro da câmara de combustão é proporcional à rotação do motor e aumenta conforme a velocidade de propagação da chama. ${ }^{17-19}$

*e-mail: rcv@ufrgs.br
O conhecimento da relação ar/combustível pode ser utilizado no mapeamento das formulações de combustíveis com a finalidade de ajustar a operação do motor, melhorando seu desempenho e reduzindo as emissões de contaminantes atmosféricos. Um motor ciclo Otto pode operar em razões de mistura ar/combustível, lambda $(\lambda)$, desde a região rica (excesso de combustível, $\lambda<1$ ) até a região pobre (excesso de oxigênio, $\lambda>1$ ), passando pelo ponto estequiométrico $(\lambda=1)$.

A utilização de combustíveis em veículos automotores nos grandes centros urbanos é crítica, devido ao grande volume de contaminantes atmosféricos emitidos. ${ }^{19}$ As duas fontes de emissões de hidrocarbonetos nos automóveis são as evaporativas, devido à elevada pressão de vapor dos combustíveis, e os hidrocarbonetos não queimados do processo de combustão. Os veículos movidos a gasolina contribuem com $50 \%$ ou mais das emissões de compostos orgânicos voláteis (VOC's). ${ }^{20}$ Os VOC's e os óxidos de nitrogênio $\left(\mathrm{NO}_{\mathrm{x}}\right)$ na presença da luz solar são responsáveis pela "névoa" fotoquímica, formando produtos de oxidação que causam irritação aos olhos, ao aparelho respiratório e danos às plantas. ${ }^{21-24} \mathrm{O}$ tipo e a composição do combustível utilizado nos automóveis influenciam, de modo significativo, nas diferentes formas de contaminação às quais o meio ambiente está sujeito. Motores a álcool produzem elevados níveis de emissões de aldeídos (principalmente formaldeído e acetaldeído). ${ }^{13}$ Os aldeídos e outros compostos carbonílicos, diretamente emitidos para a atmosfera, participam como precursores de reações fotoquímicas, produzindo ácido nítrico e nitrato de peroxiacetila (PAN). ${ }^{13} \mathrm{O}$ drástico aumento das emissões de dióxido de carbono $\left(\mathrm{CO}_{2}\right)$, a partir dos anos 70, tem influenciado diretamente no aumento do efeito estufa..$^{9,19}$

Este trabalho apresenta resultados da avaliação do rendimento térmico e da formação de monóxido de carbono e de óxido de nitrogênio em formulações com etanol, terc-amil etil éter (TAEE) e metil terc-butil éter (MTBE). A avaliação foi realizada através da utilização de formulações de 5, 10 e $15 \% \mathrm{~m} / \mathrm{m}$ dos compostos oxigenados em uma gasolina base (Gb). O etanol é um composto oxigenado, proveniente da biomassa, tradicionalmente utilizado na formulação de gasolinas automotivas. O TAEE é um novo compos- 
to oxigenado, parcialmente bio-renovável, atualmente sem aplicação comercial, enquanto que o MTBE é um produto sintético com restrições no consumo. Os testes foram realizados utilizando-se um motor ciclo Otto com injeção eletrônica programável, cromatografia a gás com detector de condutividade térmica e quimiluminescência.

\section{PARTE EXPERIMENTAL}

\section{Materiais e métodos}

\section{Ensaios de volatilidade}

A volatilidade (expressa através da curva de destilação) da $\mathrm{Gb}$ e suas formulações com $10,0 \% \mathrm{~m} / \mathrm{m}$ em etanol, MTBE e TAEE foram determinadas aplicando-se a metodologia descrita nas normas padronizadas ASTM D ${ }^{25}$ ou NBR 9619.26

\section{Composição química da gasolina base $(G b)$}

A composição química da gasolina utilizada como base foi determinada por cromatografia a gás com detector de ionização de chama (FID). Os tempos de retenção das parafinas padrões utilizadas para o cálculo dos índices de retenção ${ }^{27-35}$ foram obtidos através da injeção de uma amostra padrão de nafta (Quantitative Reference Naftha Standart, 4-8265-U-Supelco). A Tabela 1 apresenta a composição da gasolina base com massa molar média de $107 \mathrm{~g} \mathrm{~mol}^{-1}$ e fórmula molecular média $\mathrm{C}_{8} \mathrm{H}_{15}$.

Tabela 1. Composição média de Gb por tipo de grupo de hidrocarbonetos e por número de carbonos, ambos em percentual molar

\begin{tabular}{lccccc}
\hline $\begin{array}{l}\mathrm{N} . \\
\text { Carbonos }\end{array}$ & Olefinas & $\begin{array}{c}\text { n-Para- } \\
\text { finas }\end{array}$ & $\begin{array}{c}\text { i-Para- } \\
\text { finas }\end{array}$ & Naftênicos & $\begin{array}{c}\text { Aromá- } \\
\text { ticos }\end{array}$ \\
\hline $\mathrm{C}_{4}$ & 0,3 & $\mathrm{ND}$ & $\mathrm{ND}$ & $\mathrm{ND}$ & $\mathrm{ND}$ \\
$\mathrm{C}_{5}$ & 9,4 & 0,4 & 0,2 & 0,3 & $\mathrm{ND}$ \\
$\mathrm{C}_{6}$ & 11,5 & $\mathrm{ND}$ & 1,3 & 0,7 & $\mathrm{ND}$ \\
$\mathrm{C}_{7}$ & 7,4 & $\mathrm{ND}$ & 5,3 & 3,2 & $\mathrm{ND}$ \\
$\mathrm{C}_{8}$ & 2,8 & 1,2 & 2,6 & 9,7 & 1,6 \\
$\mathrm{C} 9$ & 1,3 & $\mathrm{ND}$ & 5,3 & 5,1 & 4,8 \\
$\mathrm{C} 10$ & $\mathrm{ND}$ & $\mathrm{ND}$ & 3,0 & 0,3 & 10,4 \\
$\mathrm{C} 11$ & 0,1 & 0,5 & 0,7 & $\mathrm{ND}$ & 3,9 \\
$\mathrm{C} 12$ & 1,0 & 0,3 & 1,5 & 0,1 & 1,5 \\
$\mathrm{C} 13$ & 0,4 & 0,1 & $\mathrm{ND}$ & $\mathrm{ND}$ & 0,2 \\
$\mathrm{C}_{14}$ & 0,2 & 0,1 & $\mathrm{ND}$ & $\mathrm{ND}$ & 0,8 \\
$\mathrm{C}_{15}$ & 0,4 & 0,2 & $\mathrm{ND}$ & $\mathrm{ND}$ & 0,1 \\
Total & 34,8 & 2,7 & 20,0 & 19,2 & 23,3 \\
\hline
\end{tabular}

ND significa não detectado ou percentual molar menor que 0,1

\section{Metodologia aplicada para ensaios em motor}

\section{Testes de desempenho em motor}

$\mathrm{O}$ efeito dos compostos oxigenados na formulação de gasolinas com relação à eficiência do processo de combustão foi avaliado em ensaios de consumo específico (massa de combustível alimentando o motor por unidade de trabalho produzido) do combustível. Nestes ensaios foram efetuadas medidas de potência (energia por unidade de tempo) do conjunto motor/gerador e a vazão de combustível (massa alimentada na unidade tempo). A relação entre a vazão mássica de combustível e a potência dissipada forneceu a massa de combustível por unidade de energia dissipada. As medidas do consumo específico de combustível foram realizadas utilizando um motor monocilindro de $250 \mathrm{~cm}^{3}$ de cilindrada e potên- cia nominal de 7,5 Hp (4000 W). Este motor foi acoplado a um gerador de energia elétrica. A energia elétrica produzida no gerador alimentou um banco de resistências, onde a tensão (voltagem) e a corrente (amperagem) elétrica produzidas foram registradas continuamente em um sistema de aquisição de dados via computador. O produto da voltagem pela corrente elétrica forneceu a potência dissipada no banco de resistências. A vazão mássica de combustível foi obtida mediante a utilização de uma célula de carga acoplada ao sistema de aquisição de dados. O peso do cilindro de alimentação em função do tempo forneceu uma reta com coeficiente angular igual à vazão mássica média.

Para a amostragem dos gases de descarga foi utilizado um sistema de compressão/resfriamento, que condensou a maior parte da fração líquida gerada no processo de combustão. Os gases de descarga, desta forma, foram secos, comprimidos e armazenados em cilindros de inox com volume de $50 \mathrm{~L}$ na pressão de 10 bar. O motor foi ajustado para operar na rotação de 3000 rpm e ângulo de ignição antes do ponto morto superior (APMS) de $30^{\circ}$.

\section{Composição dos gases de descarga}

$\mathrm{Na}$ combustão, o componente reagente do ar é o oxigênio. O restante dos gases existentes no ar é considerado inerte (nitrogênio e argônio). O ar contém 20,9\% de oxigênio, 78,6\% de nitrogênio, $0,5 \%$ de argônio em volume e outros gases raros que estão presentes em traços. Para determinar a estequiometria da reação de combustão foi necessário o conhecimento da composição do combustível e dos gases de descarga.

\section{Análise dos gases de descarga}

\section{Determinação de monóxido e dióxido de carbono, oxigênio, hidrogênio, nitrogênio}

Os gases de descarga monóxido e dióxido de carbono, oxigênio, hidrogênio e nitrogênio foram analisados por cromatografia a gás com coluna empacotada e detector de condutividade térmica. Colunas de peneira molecular e hélio, como gás de arraste, foram utilizados para obtenção dos sinais referentes ao oxigênio, nitrogênio e monóxido de carbono. Com argônio, por sua vez, os sinais obtidos corresponderam aos do hidrogênio, oxigênio e nitrogênio. Para a detecção de dióxido de carbono, utilizou-se hélio como gás de arraste e coluna cromatográfica empacotada Porapaq Q. Para a obtenção do percentual de cada gás analisado, os sinais foram integrados. Nos três sistemas ocorreu a detecção do nitrogênio e, considerando sua constância, obteve-se uma boa correlação entre este gás e monóxido de carbono, dióxido de carbono e oxigênio. O percentual de hidrogênio foi determinado por meio de uma mistura padrão com 5,0\% molar de hidrogênio em argônio. A partir da fórmula molecular do combustível e da composição do gás de descarga em relação ao oxigênio, hidrogênio, dióxido de carbono e monóxido de carbono, obteve-se a estequiometria da reação.

\section{Determinação do óxido de nitrogênio}

A análise do óxido de nitrogênio foi efetuada pelo método de quimiluminescência, uma vez que esse método possui alta seletividade e sensibilidade para análise do referido óxido. O sistema consistiu em uma célula de reação, a $60{ }^{\circ} \mathrm{C}$, na qual o óxido de nitrogênio e o ozônio reagiram emitindo um fóton, detectado em uma fotomultiplicadora. O ozônio foi produzido em uma câmara de alta tensão. A célula de reação foi alimentada simultaneamente com o ozônio e a amostra; o sinal de tensão da fotomultiplicadora foi convertido em concentração através de uma curva de calibração. 


\section{RESULTADOS E DISCUSSÃO}

O desempenho do motor, de uma forma mais ampla, não está limitado somente ao torque e à potência desenvolvida. Aspectos, como consumo do combustível, níveis de emissões de contaminantes atmosféricos e manutenção, devem ser considerados na avaliação do combustível mais adequado para um motor específico.

\section{Volatilidade}

A Figura 1 apresenta os perfis das curvas de destilação da gasolina base e suas formulações com $10 \% \mathrm{~m} / \mathrm{m}$ de etanol, TAEE e MTBE. O etanol com ponto de ebulição de $78^{\circ} \mathrm{C}$ reduz a temperatura de ebulição da mistura hidrocarbonetos/etanol devido à formação de azeótropos de mínima temperatura. Como se observa, ocorre uma redução significativa da temperatura de ebulição, formando um patamar no perfil da curva de destilação praticamente estável entre 50 e $60{ }^{\circ} \mathrm{C}$, facilitando a vaporização do combustível no coletor de admissão. O MTBE, que possui temperatura de ebulição de $55^{\circ} \mathrm{C}$, reduz a temperatura do evaporado no intervalo entre 60 e $120^{\circ} \mathrm{C}$. Esta redução também pode ser atribuída à formação de azeótropos entre o MTBE e hidrocarbonetos, ${ }^{8}$ porém com menor intensidade em relação ao etanol. O TAEE, com temperatura de ebulição de $102{ }^{\circ} \mathrm{C}$ e estrutura química similar aos hidrocarbonetos constituintes da gasolina, desloca o perfil da curva de destilação da gasolina base para maiores temperaturas. Este efeito é justificado em função do TAEE apresentar maior peso molecular e temperatura de ebulição.

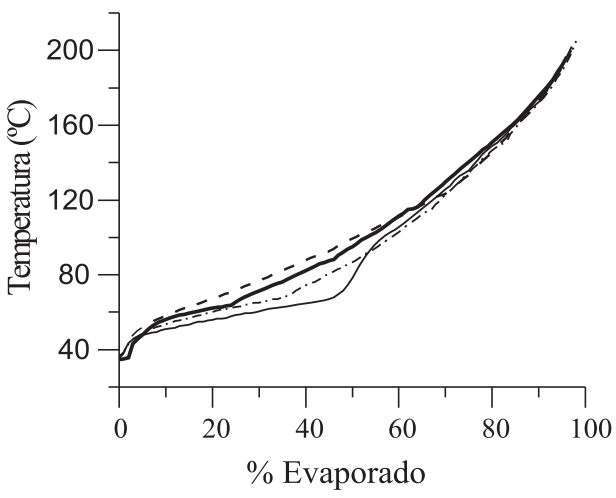

Figura 1. Perfis das curvas de destilação da gasolina base (-) e suas formulações com 10,0\% m/m de etanol (—), MTBE (- - ) e TAEE (——)

\section{Ensaios de desempenho em motor}

$\mathrm{O}$ consumo específico $\left(\mathrm{g} \mathrm{kWh}^{-1}\right)$ em função da relação ar/combustível $(\lambda)$ para a Gb, apresentado na Figura 2, é mínimo na região próxima à relação estequiométrica, devido à combustão completa, aumenta ligeiramente na região de queima pobre $(\lambda=1,1)$ devido ao excesso de ar utilizado e aumenta, também, na região de queima rica $(\lambda=0,8)$ devido à combustão incompleta.

Na Figura 3, são apresentadas tendências do consumo específico relativo em função do percentual mássico do composto utilizado nas formulações com a gasolina base $(\mathrm{Gb})$. O valor unitário corresponde ao consumo específico idêntico à Gb. A Figura 3 apresenta os resultados das formulações com etanol, onde se pode constatar que o consumo específico aumenta proporcionalmente com a concentração de etanol. Esse aumento é minimizado nos ensaios realizados com a relação ar/combustível na região de queima pobre. Os resultados obtidos nas formulações preparadas com MTBE, apresentados na Figura 3, de forma análoga ao etanol, tendem a

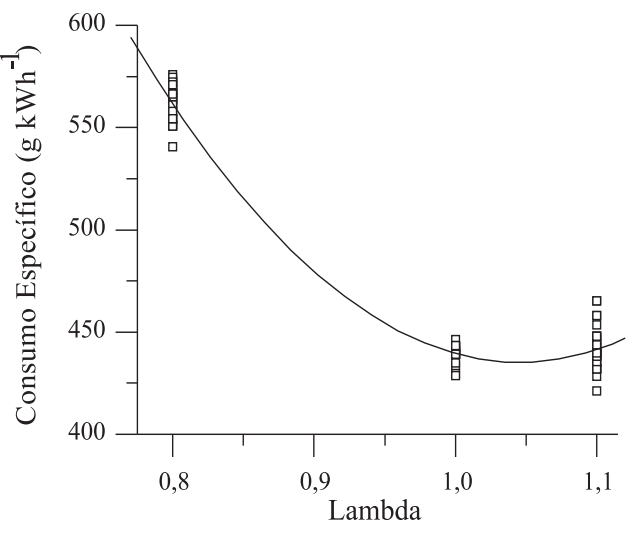

Figura 2. Efeito da relação ar/combustível no consumo específico $\left(g \mathrm{~kW} \mathrm{~h} \mathrm{~h}^{-1}\right)$ para a $G b$

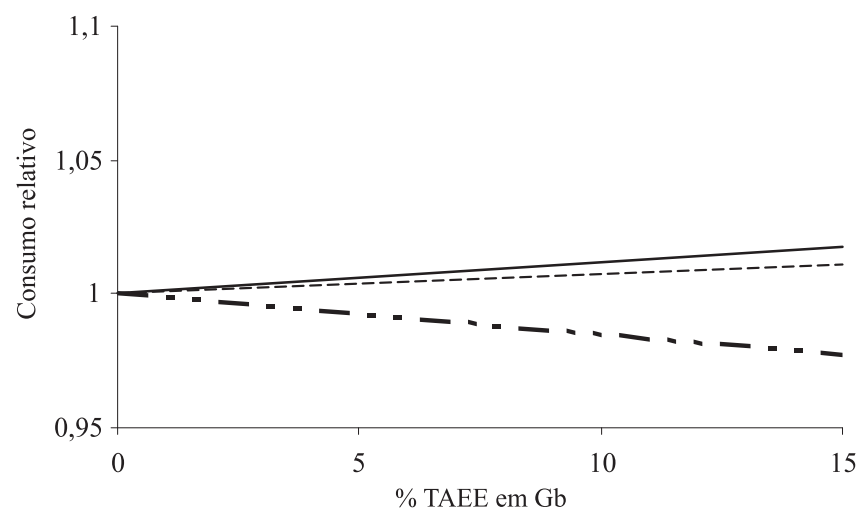

Figura 3. Consumo relativo de combustivel em função do percentual de compostos oxigenados: (a) etanol, (b) MTBE e (c) TAEE adicionados na gasolina utilizada como base (Gb) nas regiões de queima rica $(\lambda=0,8 ;-----)$, estequiométrica $(\lambda=1,0 ;-)$ e pobre $(\lambda=1,1 ;---)$

aumentar o consumo, porém, com menor intensidade, uma vez que a entalpia de combustão do MTBE é superior a do etanol.

Os ensaios realizados com as formulações com TAEE, apresentados na Figura 3, tendem a reduzir o consumo específico, principalmente quando o motor opera na região de queima pobre. As diferenças observadas são no máximo de $5 \%$ e estão muito próximas da dispersão em torno do valor médio. Entretanto, a tendência é coerente com as diferenças nos valores das entalpias de combustão dos compostos oxigenados utilizados nas formulações. A entalpia de combustão, para um grande número de hidrocarbonetos e frações provenientes do petróleo, situa-se entre 40 e $45 \mathrm{MJ} \mathrm{kg}^{-1}$. A presença de oxigênio na molécula tende a reduzir a entalpia de combustão. A entalpia de combustão do etanol é $29 \mathrm{MJ} \mathrm{kg}^{-1}$, para o MTBE e TAEE são próximas a $36 \mathrm{MJ} \mathrm{kg}^{-1}$.

Outro aspecto importante a considerar no rendimento térmico do ciclo é a velocidade de propagação da chama. Os compostos MTBE e TAEE são éteres de cadeia ramificada, e suas velocidades de propagação da chama são, aproximadamente, $70 \%$ em relação à velocidade de propagação da chama do etanol. ${ }^{36} \mathrm{~A}$ utilização do avanço da ignição adequado pode contribuir para minimizar o aumento do consumo de formulações com etanol. A redução do consumo específico observado para o TAEE pode ser atribuída a sua menor velocidade de propagação da chama. Em sistemas que operam com rotação e ângulo de ignição fixo, quanto maior a velocidade de propagação da chama, maior deverá ser o trabalho negativo de compressão. Utilizando o avanço de ignição adequado, podese minimizar o trabalho negativo, otimizando o máximo de pres- 
são no interior da câmara de combustão para que esta ocorra próxima a $15^{\circ}$ após o ponto morto superior e maximizando o torque. ${ }^{18}$

\section{Composição dos gases de descarga}

Devido a efeitos cinéticos e de equilíbrio, a composição final dos gases de descarga no processo de combustão é uma mistura complexa de vários componentes. Em misturas ricas, a quantidade de oxigênio disponível é insuficiente para a oxidação completa do combustível, ocorrendo a formação de produtos, como monóxido de carbono e hidrocarbonetos não queimados ou parcialmente queimados em concentrações elevadas. Em misturas pobres, ocorre uma redução significativa na concentração de monóxido de carbono e hidrogênio. Devido às elevadas temperaturas na câmara de combustão, ocorre, inevitavelmente, a formação de óxidos de nitrogênio, provenientes da reação entre o nitrogênio e o oxigênio do ar atmosférico.

\section{Emissões de monóxido de carbono e hidrogênio}

A Figura 4a apresenta o percentual de monóxido de carbono (CO), enquanto a Figura $4 \mathrm{~b}$ o de hidrogênio $\left(\mathrm{H}_{2}\right)$ presentes nos gases de descarga da combustão de $\mathrm{Gb}$ e suas formulações com $10,0 \% \mathrm{~m} / \mathrm{m}$ de etanol, MTBE e TAEE em função do lambda $(\lambda)$. O hidrogênio provêm do craqueamento dos hidrocarbonetos na câmara de combustão e pelo deslocamento da reação do "vapor d'água". ${ }^{18,19}$ Quando o motor está operando com misturas deficientes em oxigênio, em relação à quantidade estequiométrica, as emissões de monóxido de carbono e hidrogênio são mais elevadas. Em contrapartida, com misturas ricas em oxigênio, a combustão é completa e as quantidades de monóxido de carbono e hidrogênio são minimizadas. A reação de oxidação do monóxido de carbono é reversível a temperaturas elevadas; desta forma, este gás está sempre presente, em maior ou menor quantidade, nos gases de descar-

(a)

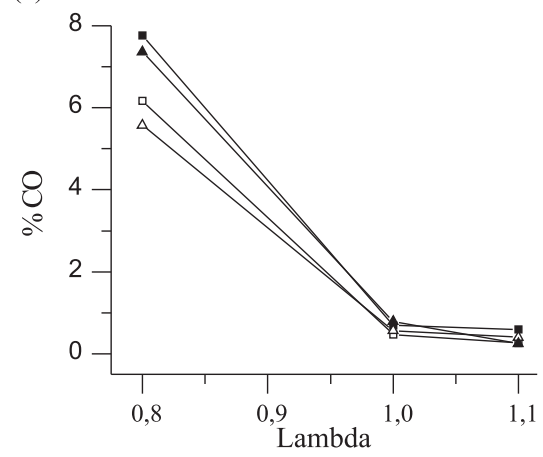

(b)

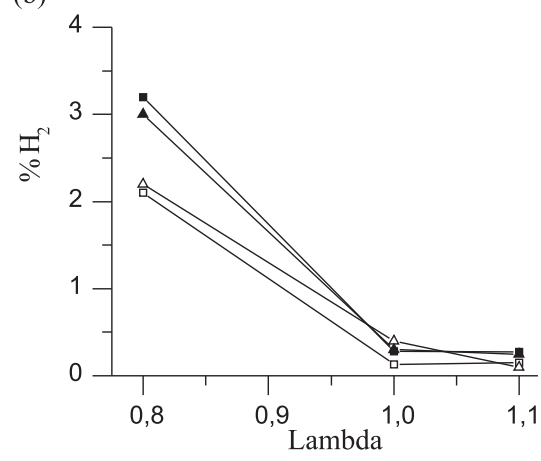

Figura 4. Percentual de (a) $\mathrm{CO}$ e (b) $\mathrm{H}_{2}$ presentes nos gases de descarga da combustão de $G b(-)$ e suas formulações com etanol $(\square), \operatorname{MTBE}(\mathbf{\Delta})$ e TAEE $(\triangle)$, com relação ao lambda $(\lambda)$ ga. Para os ensaios realizados $\operatorname{com} \lambda=0,8$ a utilização dos compostos oxigenados diminuiu as emissões de monóxido de carbono, em aproximadamente $25 \%$ para MTBE e TAEE e $5 \%$ para o etanol.

\section{Emissões de óxido de nitrogênio (NO)}

A Figura 5 apresenta o nível de óxido de nitrogênio (ppm) presente nos gases de descarga da combustão de Gb e suas formulações com etanol, MTBE e TAEE em função da relação ar/combustível $(\lambda)$. Quando o motor opera com misturas deficientes em oxigênio, as emissões de óxido de nitrogênio são mínimas. Este fato pode ser explicado devido à combustão incompleta, com conseqüente redução da temperatura na câmara de combustão, diminuindo a velocidade de reação para formação do óxido de nitrogênio. Próximo da relação ar/combustível estequiométrica, a produção de óxido de nitrogênio é máxima, uma vez que a temperatura na câmara de combustão é muito alta. Quando o motor opera $\operatorname{com} \lambda>1$, observa-se uma redução nas emissões do óxido de nitrogênio seguindo a tendência da redução da temperatura da chama devido ao excesso de ar. $\mathrm{O}$ aumento no avanço da ignição aumenta a temperatura da câmara de combustão, aumentando as emissões de óxido de nitrogênio. As emissões do óxido de nitrogênio dependem basicamente da relação ar/combustível e taxa de compressão dos motores, sendo pouco sensíveis à composição do combustível.

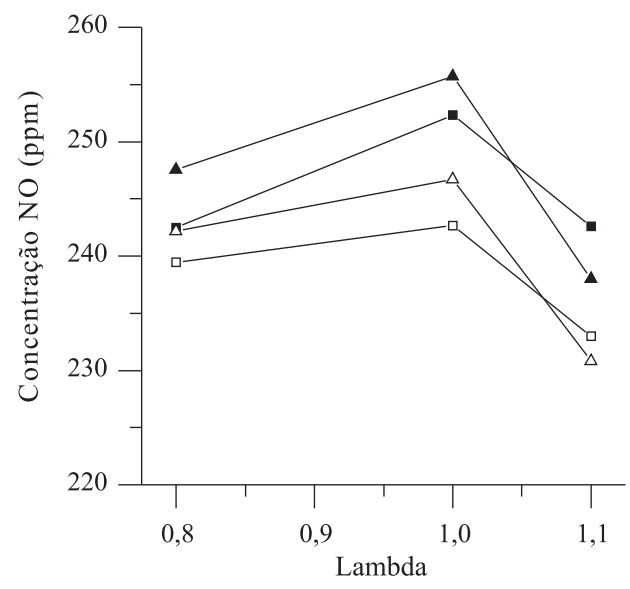

Figura 5. Concentração de NO (ppm) nos gases de descarga da combustão

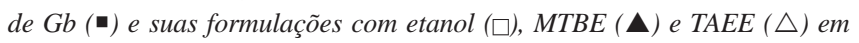
relação ao lambda $(\lambda)$

\section{CONCLUSÕES}

Gasolinas formuladas com os éteres MTBE e TAEE emitem menor percentual de monóxido de carbono quando comparadas com as formuladas com etanol. Gasolinas formuladas com o éter TAEE apresentam consumo específico similar à gasolina base. As formuladas com etanol tendem a aumentar o consumo específico de combustível em relação aos hidrocarbonetos. As emissões de óxido de nitrogênio apresentam um máximo próximo da relação ar/combustível estequiométrica e são pouco dependentes da composição do combustível.

\section{MATERIAL SUPLEMENTAR}

A Figura 1S, disponível em http://quimicanova.sbq.org.br, na forma de arquivo PDF com acesso gratuito, representa esquematicamente o sistema para avaliação do desempenho dos combustíveis em ensaios com motor. 


\section{AGRADECIMENTOS}

Ao CNPq, pelo apoio financeiro, e à Petrobras, pela doação da gasolina utilizada neste trabalho.

\section{REFERÊNCIAS}

1. Tanaka, S.; Ayala, F.; Keck J. C.; Heywood, J. B.; Combust. Flame 2003, 132, 219.

2. Chiaramonti, D.; Oasmaa, A.; Solantausta, Y.; Renewable and Sustainable Energy Reviews 2007, 11, 1056.

3. Braun, S.; Apple, L. G.; Schmall, M.; Quim. Nova 2004, 27, 472.

4. Al-Haran, A.; Energy Conversion and Management 2003, 44, 1547.

5. Agarwal, A. K.; Progress in Energy and Combustion Science 2007, 33, 233.

6. Chomorro, C. R.; Martin, M. C.; Villamanan, M. A.; Segovia, J. J.; Fluid Phase Equilib. 2004, 220, 105.

7. Vinuesa, J. F.; Mirabel, Ph.; Ponche, J. L.; Atmos. Environ. 2003, 37, 1757.

8. de Menezes, E. W.; da Silva, R.; Cataluña, R.; Ortega, R. J. C.; Fuel 2006, 85,815 .

9. da Silva, R.; Cataluña, R.; Menezes, E. W. de; Samios, D.; Piatnicki, C. M. S.; Fuel 2005, 84, 951 .

10. Wheals, A. E.; Basso, L. C.; Alwes, D. M. G.; Amorim, H. V.; Trends Biotechnol. 1999, 17, 482.

11. Niven, R. K.; Renewable and Sustainable Energy Reviews 2005, 6, 535

12. Prasad, R.; Kennedy, L. A.; Ruckenstein, E.; Catal. Rev. - Sci. Eng. 1984, $26,1$.

13. Tanner, R. L.; Miguel, A. H.; Andrade, J. B.; Gaffney, J. S.; Streit, E.; Environ. Sci. Technol. 1998, 22, 1026.

14. Cataluña, R.; Silva, R.; Quim. Nova 2006, 29, 580.

15. Vilar, R. B. C.; da Silva, R.; Schosssler, P.; Vese, R. C.; Piatnicki, C. M. S.; Samios, D.; Caramao, E. B.; J. Chromatogr., A 2003, 985, 367.

16. Owen, K.; Coley, T.; Automotive Fuels Reference Book, Society of Automotive Engineers, Inc.: USA, 1995.
17. Giacosa, D.; Motores Endotérmicos, Ed. Científico-Médico: Barcelona, 1986.

18. Heywood, J. B.; Internal Combustion Engine Fundamentals, McGraw-Hill New York, 1988.

19. Guibet, J.; Faure-Birchem, E.; Fuels and Engines, Editions Technip: Paris, 1999.

20. Watson, J. G.; Chow, J. C.; Fujita, E. M.; Atmos. Environ. 2001, 35, 1567.

21. Consul, J. M. D.; Thiele, D.; Veses, R. C.; Baibich, I. M.; Dallago, R. M.; Quim. Nova 2004, 27, 432.

22. Alloway, B. J.; Ayres, D. C.; Chemical Principles of Environmental Pollution, Blackie Academic \& Professional: London, 1994.

23. Rangel, M. do C.; Carvalho, M. F. A.; Quim. Nova 2003, 26, 265.

24. Mazzarino, I.; Barresi, A. A.; Catal. Today 1993, 17, 335.

25. ASTM, American Society for Testing and Material, ASTM Committee of Standards, West Conshohocken; Standard Test Method for Distillation of Petroleum Products, ASTM D 86, 2003.

26. ABNT NBR, Associação Brasileira de Normas Técnicas; Produtos de Petróleo-Determinação das Propriedades de Destilação, NBR 9616, 1998.

27. ASTM, American Society for Testing and Materials; Standard Test Method for Detailed Analysis of Petroleum Naphtas trrough n-Nonane by Capillary Gas Chromtography - ASTM D 5134, 1998.

28. Miller, R. L.; Ettre, L. S.; J. Chromatogr. 1983, 259, 393.

29. Wherli, A.; Kováts, E.; Helv. Chim. Acta 1959, 42, 2709.

30. Harris, D. C.; Quantitative Chemical Analyses, $5^{\text {th }}$ ed., W. H. Freeman and Company: New York, 1999.

31. Altenburg, K.; J. Chromatogr. 1969, 44, 167.

32. Varian Analytical Instruments 2700 Mitchell Drive Walnut Creek, CA 94598-1675; Varian Detailed Hydrocarbon Analysis; Version 5.0, U.S.A., 2000 .

33. Petrocol TM DH Columns Catalog $\mathrm{N}^{\circ} 2-4160$, SUPELCO, 1996.

34. Durand, J. P.; Boscher, Y.; Petroff, N.; J. Chromatogr. 1987, 395, 229.

35. Dietz, W. A.; J. Chromatogr. 1967, February, 68.

36. Wildner, F. D.; Dissertação de Mestrado, Universidade Federal do Rio Grande do Sul, Brasil, 2006. 
RENDIMENTO TÉRMICO E EMISSÕES DE CONTAMINANTES ATMOSFÉRICOS DE GASOLINAS FORMULADAS COM ETANOL, MTBE E TAEE

Rosângela da Silva, Eliana Weber de Menezes e Renato Cataluña*

Departamento de Físico-Química, Instituto de Química, Universidade Federal do Rio Grande do Sul, Av. Bento Gonçalves, 9500, 91501-970 Porto Alegre - RS, Brasil

Central de Monitoramento

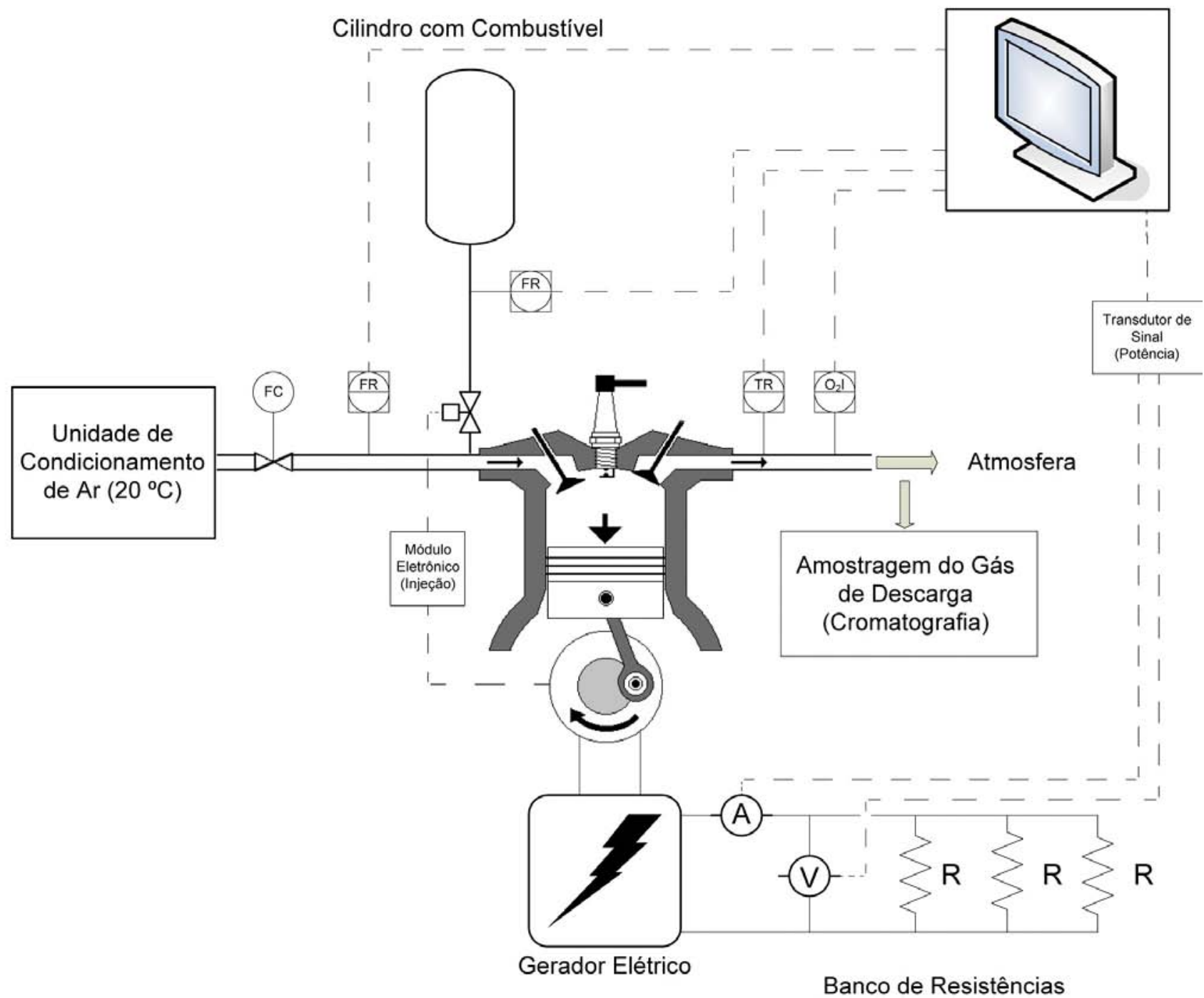

Figura 1S. Sistema para avaliação do desempenho dos combustíveis em ensaios com motor 